\title{
A Histological and Immuno-Histchemical Study on the Effect of Atorvastatin Versus Adipose Derived Stem Cells on Cutaneous Wound Healing in Diabetic Male Albino Rats
}

\section{Original Article}

\author{
Abeer Fouad Abd Elmohsen ${ }^{1}$, Nagla Mohamed Salama ${ }^{1}$, Dalia Hussien Abdelaziz ${ }^{2}$, \\ Azza Saleh Embaby ${ }^{2}$ and Eman Mohammed Mohammed Abd Elhameed ${ }^{2}$
}

Department of Histology, Faculty of Medicine, ${ }^{1}$ Cairo University, ${ }^{2}$ Beni-Suef University, Egypt

\begin{abstract}
Background: About $15 \%$ of the 150 million people with diabetes worldwide suffer from foot ulcerations, which often become non-healing chronic wounds. Atorvastatin has anti-inflammatory, fibro proliferative, microvascular pleiotropic properties and able to control wound healing process. Adipose-derived stem cells (ADSCs) provide an attractive source of cell therapy for regeneration of damaged skin being able to self-renewal and differentiating into various cells.

Aim of the Work: To evaluate and compare the effect of atorvastatin versus ADSCs on cutaneous wound healing in diabetic rats.

Materials and Methods: 85 adult male albino rats one for ADSCs preparation and others were divided into six groups each of them was subdivided into subgroups a \& b as follow: Subgroup a was sacrificed after 7 days of wounding. Subgroup b was sacrificed after 14 days of wounding. GI control, GII (wounded, non-diabetic rats), GIII (non-treated, wounded diabetic group), GIV (Vaseline and lanoline treated wounded diabetic), GV (ADSCs treated, wounded diabetic rats) injected with single intradermal ADSCs at the edge of the wound one day post wounding. GVI (atorvastatin treated wounded diabetic rats). Skin specimens were taken from the wound site, processed and stained with H\&E, Masson's trichrome and immunohistochemical stain for vascular endothelial growth factor (VEGF).

Results: Wounds of diabetic groups (III \&IV) showed delayed healing of wound as compared to the non diabetic group II with failure of re-epithelization and weak to moderate positive VEGF immunoreactions. Whereas, groups treated with atorvastatin or ADSCs exhibited better healing of the wound. However ADSCs group (V) showed better organization of collagen together with reappearance of skin appendages which were missed in atorvastatin group (VI).

Conclusion: Both atorvastatin and ADSCs proved a definite ameliorating effect on the wound healing of diabetic rats. However, ADSCs administration denoted a more remarkable therapeutic healing effect compared to Atorvastatin.
\end{abstract}

Received: 04 May 2020, Accepted: 25 May 2020

Key Words: ADSCs, atorvastatin, diabetic, rat, wound healing.

Corresponding Author: Eman Abd El Hamid, MSc, Department of Histology, Faculty of Medicine, Bani Suef University, Egypt, Tel.: +20 1282414244, E-mail: emanabdelhamed79@yahoo.com

ISSN: 1110-0559, Vol. 44, No.1

\section{INTRODUCTION}

Wound healing involves a complex chain of events which interact with different cells and tissues. It comprises three overlapping phases: inflammatory, proliferative, and remodeling which requires well-coordinated interplay of cell-signaling. This interplay is impaired in a number of medical conditions, including diabetes. Treatments of chronic wounds remain unsatisfactory increasing the need for more effective new treatment strategies ${ }^{[1,2]}$.

Diabetes mellitus (DM) is a serious chronic metabolic disorder leads to diabetic vascular complications. These complications can injure some important tissues such as kidney, heart, and arteries. Diabetic foot ulcer (DFU) is one of the most serious complications in diabetic patients due to its particular difficulty to heal ${ }^{[3]}$. It consists of lesions in deep tissues associated with neurological disorders and peripheral vascular diseases in the lower extremities. DFU is associated with increased disability rate and mortality ${ }^{[4]}$.

Undifferentiated cells for cell-based tissue repair and regeneration giving a new approach for chronic wound healing strategies ${ }^{[5]}$. Mesenchymal stem cells have been proved to enhance cell regeneration rather than fibrosis at the wound site, mainly through paracrine signaling with the surrounding cells/tissues ${ }^{[2]}$. Adipose derived stem cells (ADSCs) appear to be an ideal population of stem cells because they are autologous, non-immunogenic, plentiful, and easily obtained. Both preclinical and clinical studies have revealed that ADSCs have potential for wound healing ${ }^{[5]}$.

Statins have exhibited an anti-inflammatory action in acute model of skin inflammation ${ }^{[6]}$. Atorvastatin (3-hydroxy-3-methylglutaryl coenzyme A reductase inhibitor) shows promise for wound healing ${ }^{[7]}$. It has been also reported to exert vasculo-protective action in diabetes 
which is mediated by maintenance and restoration of endothelial function via several mechanisms ${ }^{[8]}$.

The present study aimed to evaluate and compare the effect of atorvastatin versus ADSCs on cutaneous wound healing in diabetic albino rats.

\section{MATERIALS}

\section{1-Drugs}

\section{A. Streptozotocin (STZ)}

STZ was purchased from Sigma company in $0.1 \mathrm{~mol} / \mathrm{L}$ ice-cold citric acid-sodium citrate buffer, $\mathrm{pH} 4.5^{[3]}$.

\section{B. Atorvastatin}

The original drug powder was obtained from Egyptian International Pharmaceutical Industries (EIPICO) company in the form of powder then it was transformed into cream form 5\% as follow:- $5 \mathrm{gm}$ of statin powder in $95 \mathrm{gm} \mathrm{1:1}$ mixture of lanolin and vaseline as a cream base $\mathrm{e}^{[7]}$.

\section{2-Adipose-Derived Stem Cells (ADSCs) ${ }^{[9]}$}

Single intradermal injection of $0.1 \mathrm{ml}$ PBS containing $1 \times 10^{6}$ labeled ADSC at the edge of the wound.

ADSCs were Isolated from rat abdominal subcutaneous fat and then cultured. They were detected of by their adhesiveness, fusiform shape, specific surface marker and by their characterization like CD45 and CD29 (eBioscience, San Diego, CA, USA). Detection was by flow cytometry analyses using antibody concentrations which were recommended by the manufacturers ${ }^{[10]}$. Labeling of stem cells with PKH26 dye were performed according to the manufacturer's instructions, ADSCs cells were harvested during the 3rd passage and were labeled with PKH26 fluorescent linker dye (Sigma-Aldrich, Saint Louis, USA, Catalog Number: PKH26GL) ${ }^{[11]}$. All steps were performed at the Unit of Biochemistry and Molecular Biology at Medical Biochemistry Department, Faculty of Medicine, Cairo University, Egypt ${ }^{[12,13]}$.

\section{3-Animals}

The study was carried on eighty five adult male albino rats ranging from 40 to 44 days age weighing from 200 to $250 \mathrm{gm}$ each. The animals were housed in the Animal House of Histology Department, Faculty of Medicine, Cairo University under good hygienic conditions of air, temperature, fed ad libitum and allowed for free water supply. The animals were treated according to the ethical guidelines of Cairo University. One rat for preparing ADSCs. Eighty four rats were divided randomly into six groups as follow:-

\section{Group I (control, non wounded non diabetic group)}

Twenty four controls non-wounded non diabetic rats received single intraperitoneal injection (IP) of $0.1 \mathrm{~mol} / \mathrm{L}$ ice-cold citric acid-sodium citrate buffer, $\mathrm{pH} 4.5$ then subdivided into:

- Twelve of the rats received $0.1 \mathrm{ml} \mathrm{PBS}$ as one intradermal injection at the right upper quadrants of the back of the rats. Six rats were sacrificed with subgroups a (7 days subgroups) and the other six were sacrificed with subgroups b (14 days subgroups)

- Twelve of the rats received daily topical cream formed of mixture of vasline and lanoline at the right upper quadrants of the back of the rats. Six of them were sacrificed with subgroups a (one week subgroups) and the other six were sacrificed with subgroups b (14 days subgroups).

The animals of other groups are subjected to wound as follow:

\section{Wound creation}

The animals were anesthetized using (IP) injection of ketamine $100 \mathrm{mg} / \mathrm{kg}$ of body weight - and xylazine at 10 $\mathrm{mg} / \mathrm{kg}^{[14]}$. A full-thickness excisional wound with $15 \mathrm{~mm}$ diameter using a sharp blade was made on right upper quadrant of the back of the animals. Intramuscular antibiotic (penicillin $5 \mathrm{mg} / \mathrm{kg}$ ) and intramuscular analgesic and anti-inflammatory (Meloxicam. $2 \mathrm{mg} / \mathrm{kg}$ ) were administered for three consecutive days after wound induction. The day of wound creation was considered as day 0 .

\section{Group II (wounded non diabetic group)}

Twelve rats were injected with single (IP) injection of $0.1 \mathrm{~mol} / \mathrm{L}$ ice-cold citric acid-sodium citrate buffer, $\mathrm{pH}$ 4.5. Wound is created after 72 hours. Then, the rats received $0.1 \mathrm{ml}$ PBS as single intradermal injection at the wound edges. They received daily topical cream formed of mixture of vasline and lanoline on the wound. Six of them were sacrificed one week after wounding (subgroup a) and the other six rats were sacrificed 2 weeks after wounding (subgroup b).

\section{Induction of diabetes}

Forty eight animals each received single IP injection of streptozotocin $(\mathrm{STZ}$; in $0.1 \mathrm{~mol} / \mathrm{L}$ ice-cold citric acidsodium citrate buffer, $\mathrm{pH} 4.5$ ) at dose of $70 \mathrm{mg} / \mathrm{kg}^{[3]}$. After 72 hours of STZ administration, blood samples from the tail vein were collected for measuring glucose levels. Diabetes was diagnosed when blood glucose concentration $>16.7$ $\mathrm{mmol} / \mathrm{L}$. After diagnosis of diabetes wound was created as described above. The animals were then randomly equally classified into four groups:

\section{GpIII (non treated wounded diabetic group)}

Twelve rats were injected with $0.1 \mathrm{ml}$ PBS once intradermally at the edge of the wound. Six of them were sacrificed after 7 days of wounding (subgroup a) and the 
other six rats were sacrificed after 14 day of wounding (subgroup b)

\section{GpIV (Vasline and Lanoline Treated Wounded Diabetic Group)}

The wounds of rats of this group were treated with Vaseline and lanoline cream daily. Six of them were sacrificed after 7 days of wounding (subgroup a) and the other six rats were sacrificed after 14 day of wounding (subgroup b)

\section{GpV(ADSCs Treated Wounded Diabetic Group)}

Twelve rats were injected once intradermally at the wound edges at a dose of $1 \times 106$ ADSCs (in $0.1 \mathrm{ml}$ PBS) one day post wounding. Six of them were sacrificed after 7 days of wounding (subgroup a) and the other six rats were sacrificed after 14 day of wounding (subgroup b).

\section{Gp VI (Atorvastatin Treated Wounded Diabetic Group)}

The wounds of diabetic rats of this group were treated daily with $5 \%$ atorvastatin cream. Six of them were sacrificed after 7 days of wounding (subgroup a) and other six rats were sacrificed after 14 day of wounding (subgroup b).

At time of sacrifice, Animals were anesthetized using ketamine $100 \mathrm{mg} / \mathrm{kg}$ of body weight - and xylazine at 10 $\mathrm{mg} / \mathrm{kg}^{[14]}$. Full-thickness skin specimens including about $0.5 \mathrm{~cm}$ around the healing wound were taken. Flattened skin specimens were processed for paraffin blocks. Serial sections of $5 \mu \mathrm{m}$ thickness were cut and subjected to the followings:

1. Histological study

- Hematoxylin\& Eosin staining ${ }^{[15]}$.

- Masson's trichrome staining ${ }^{[16]}$.

2. Immuno histochemical

Kits used in this study were supplied by Thermo Scientific and Lab Vision Corporation, CA 94539, USA for staining for $\mathrm{VEGF}^{[17]}$.

\section{Anti VEGF}

It is a mouse monoclonal primary antibody, [code MA116629 Isotype: Mouse/ IgG1, Kappa, cloneVG1 (Ready to use for immunohistochemical staining)] for the detection of proliferating blood vessels. This antibody reacts with VEGF in human, mouse, rat and canine samples. It was supplied in a liquid form and should be stored at $4 \bowtie \mathrm{c}$ short term. For long term storage, store at $-20 \bowtie c$, avoiding freeze/ thaw cycles. The cellular staining pattern for VEGF is cytoplasmic.

\section{Detection System}

Ultravision large volume detection system: Anti -polyvalent kit (ready to use); [catalogue number TP -060 -HL].

\section{2) Diaminobenzidine tetra hydrochloride (DAB) substrate system}

[Catalogue number TA -060 -HD] and was supplied as $6 \mathrm{ml}$ DAB chromogen and $6 \mathrm{ml}$ DAB substrate to be stored at $4-6^{\circ} \mathrm{C}$.

\section{Counterstain}

Mayer's hematoxylin [catalogue number TA -060 -MH] was used for counterstain. -For the detection specificity of primary antibody additional sections of skin were processed in same way but omitting steps of applying the primary antibody (negative control).

\section{(3) Detection of homing of injected cells in rat skin by fluorescent microscope}

The unstained paraffin sections from specimen of the wound site were examined with a fluorescent microscope to detect the cells stained with PKH26 dye to ensure homing and to trace the injected cells in ADSCs treated group.

\section{(4) Morphometric study and Statistical Analysis ${ }^{[18]}$}

Image analyzer of" LeicaQwin $500 \mathrm{C}$ " computer system Ltd. (Cambridge, England)used to take measurements. (Histology Department, Faculty of Veterinary Medicine, Beni-sweif University).

Epidermal thickness in standered low power fields(x100) in H\&E stained sections using interactive measurements menu.

Area percent of collagen fibers in standard low power fields (x 100) in Masson's trichrome stained sections.

3. Area percent of positive VEGF - immunopostivity in standard high power fields ( $\mathrm{x} 400$ ).

All previous measurements were taken in 10 non overlapping randomly chosen fields for all specimens of each animals of all groups. All Quantitative data were collected as means and standard deviations (SD) then compared by using one-way analysis-of-variance (ANOVA). Any significant ANOVA was followed by post hoc Tukey test to detect which pairs of groups caused the significant difference. P-values $<0.05$ were considered statistically significant. Calculations were made on SPSS software version 21(Chicago, USA).

\section{RESULTS}

No deaths were observed in all rats

\section{One week subgroups}

\section{Histological results}

\section{A. Hematoxylin and Eosin stain(Plate 1 and Table 1)}

All rats of subgroup I a (control, non-wounded non diabetic group) showed similar results and showed the well-known normal histological structure. Skin sections showed epidermal layer as a stratified squamous epithelium 
with a thickness of $54.75 \pm 3.11 \mu \mathrm{m}$ and apparent well developed epidermal rete-ridges. The dermis exhibited well organized, tightly packed collagen bundles and hair follicles with apparent sebaceous glands. Sweat acini and ducts are also present in the dermis. Skin sections in the wound of non-diabetic rats subgroup II a (wounded, non-diabetic rats) showed thin discontinuous epidermis. It decreased significantly to become $(4.76 \pm 2.32)$ compared with subgroup Ia. The dermis showed mononuclear cellular infiltrate, newly formed blood vessels, thin dispersed collagen fibers with loss of skin appendages. Otherwise, the wound area of subgroup IIIa (Non-treated wounded diabetic rats) revealed ulceration with failure of re-epithelization. The adjacent epidermis showed proliferation of keratinocytes and was seen encroaching at the edge of the wound. The wound bed was filled with cellular granulation tissue. Many neutrophils were detected at the wound area. Skin sections of subgroup Iva (vasline and lanoline treated wounded diabetic group) revealed no epidermal regeneration and some degenerative changes at the wound site. Disorganized dermal matrix and wispy thin connective tissue bundles were seen. Collagen fibers in the matrix were widely separated demonstrating edema. Some congested blood vessels, extravasated RBCs, mononuclear inflammatory cell infiltrate and thickened vessel wall were also seen. The wound area of subgroup Va (ADSCs treated wounded diabetic group) was covered with thin epidermis (19.63 \pm 1.31 , significant increase compared to III and IV) with absent rete-ridges. Granulation tissue with mononuclear cellular infiltrate and many newly formed capillaries were seen. Fibroblasts overlapping the newly formed collagen fibers were seen. The skin section of subgroup VIa (atorvastatin treated wounded diabetic group) showed that the area of the wound completely covered with epidermis (14.08 \pm 2.37 ; significant increase compared to II, III ,IV) which exhibited good degree of maturation with newly formed epidermal rete ridges. Massive granulation tissue was observed represented by newly formed collagen fibers and newly formed blood vessels. Few mononuclear inflammatory cells could be distinguished. No skin appendages were seen.

\section{B. Masson'strichrome stain (Plate 2)}

The dermis of subgroup (I a) showed well organized, tightly packed collagen bundles. The collagen bundles in papillary layer were thinner than those present in the reticular layer of the dermis which were coarse and dense. However, animals of subgroup (II a), (IIIa) exhibited thin dispersed collagen fibers. Few newly formed irregularly arranged collagen fibers appeared at the wound site of subgroups (IVa), (Va) with more density in papillary dermis.

\section{(2) VEGF immunohistochemical results (Plate 3)}

Subgroup I a (control, non-wounded non diabetic group) exhibited nearly absent immunoreactivity to VEGF in the dermis, but the positive cytoplasmic reaction was prominent in the epidermal keratinocytes. However, animals of subgroup II a (wounded, non diabetic rats) showed strong positive cytoplasmic reaction in many endothelial cells lining the newly formed blood vessels, perivascular mononuclear inflammatory cells and also in many fibroblastic cell. The reaction decreased to become moderate positive reaction and expressed in positively reacted endothelial cells, mononuclear inflammatory cells and fibroblastic cells in subgroup IIIa (Non-treated wounded diabetic rats). Furthermore, the reaction in subgroup Iva (vasline and lanoline treated wounded diabetic group), still positive to VEGF but it is faint, localized and expressed by some perivascular mononuclear inflammatory cells, endothelial cells and in some fibroblastic cells. Then, the reaction was increased in subgroup Va (ADSCs treated wounded diabetic group) to become strong positive cytoplasmic immunostaining reaction in large number of endothelial cells, fibroblastic and mononuclear inflammatory cells. Moreover, in subgroup VIa (atorvastatin treated wounded diabetic group). Skin sections exhibited moderate to strong positive immunohistochemichal reaction to VEGF in many endothelial cells, fibroblasts as well as mononuclear inflammatory cells.

\section{Two week subgroups}

\section{(1) Histological results}

\section{A. Hematoxylin and Eosin stain (Plate 4)}

The wound site in subgroup II b (wounded, non-diabetic rats) was covered by fully regenerated epidermis but with no rete-ridges. Massive granulation tissue was seen in the dermis represented by newly formed disorganized collagen fibers and newly formed blood vessels. Inflammatory cells mostly mononuclear cellular infiltrate were also detected. No skin appendages were seen.

Compared to subgroup II a, animals of this subgroup (III b; non-treated, wounded diabetic rats) showed widely separated wound edges indicating ulcer area with failed epithelial migration to cover the entire wound. The dermis showed massive infiltration of mononuclear inflammatory cells and congested blood vessels which is one of diabetic signs. In subgroup IVb (vasline and lanoline treated, wounded diabetic group) the periphery of the wound was covered by thin epidermis while the center showed absent epidermis. Mononuclear inflammatory infiltrating cells were detected mostly perivascular. The upper dermis was deficient in collagen fibers. The lower dermis showed disorganized collagen fibers with few numbers of newly formed small blood vessels.

The wound area of rats of subgroup $\mathrm{Vb}$ (ADSCs treated, wounded diabetic group) was covered with thin epidermis. The dermis showed reappearance of skin appendages in the form of newly formed hair microfollicles with central keratin and newly formed sebaceous glands. Collagen bundles appeared in different directions. Minimal inflammatory cellular infiltrate was detected. Otherwise, the wound site of rats of subgroup VIb (atorvastatin 
treated, wounded diabetic group) showed scar with no skin appendages The dermis exhibited thick collagen bundles in different directions with moderate reduction in number of newly formed blood vessels.

\section{B. Masson'strichrome stain (Plate 5)}

The wound areas of subgroubs IIb, IIIb, IVb showed thin disorganized dermis collagen fibers. While in subgroup $\mathrm{Vb}$ (ADSCs treated group), the dermis showed collagen bundles in different directions. On the other hand, thick disorganized collagen bundles were seen in the dermis of subgroup $\mathrm{VIb}$ (atorvastatin treated group).

\section{(2) VEGF immunohistochemical stain (Plate 6)}

The dermis in the wound area of subgroup II b exhibited strong widely spread immunoreactivity to VEGF as expressed by positively reacted endothelial cells, mononuclear inflammatory cells and fibroblastic cells. In subgroup IIIb, IVb moderate cytoplasmic immunoreactivity was represented by positively reacted endothelial cells, mononuclear inflammatory cells and fibroblastic cells. Moderate positive reaction to VEGF immunostaining was seen in subgroups $\mathrm{Vb}$ (ADSCs treated) and subgroup $\mathrm{VIb}$ (atorvastatin treated) represented in fibroblasts, endothelial cells and few mononuclear inflammatory cells. Added to that moderate positive reaction to VEGF appeared in newly formed sebaceous glands in subgroup $\mathrm{Vb}$.

\section{(3) Fluorescent microscopic results (Plate 7)}

PKH-labeled adipose stem cells were seen at the wound area in subgroup Va (ADSCs treated wounded diabetic group). There was more PKH labeled adipose stem cells homed in the wound area in subgroup $\mathrm{Vb}$ (ADSCs treated wounded diabetic group) comparing with subgroup $\mathrm{V}$ a.

\section{(4) Morphometric and statistical results}

a-The mean epidermal thickness, the mean area percent of collagen fiber and mean area percent for VEGF \pm standard deviation of the one week subgroups(a): (Table 1, Figures 1, 2,3).

b-The mean epidermal thickness, the mean area percent of collagen fiber and mean area percent for VEGF of the \pm standard deviation two weeks subgroups(b): (Table 2, Figures 1,2,3).

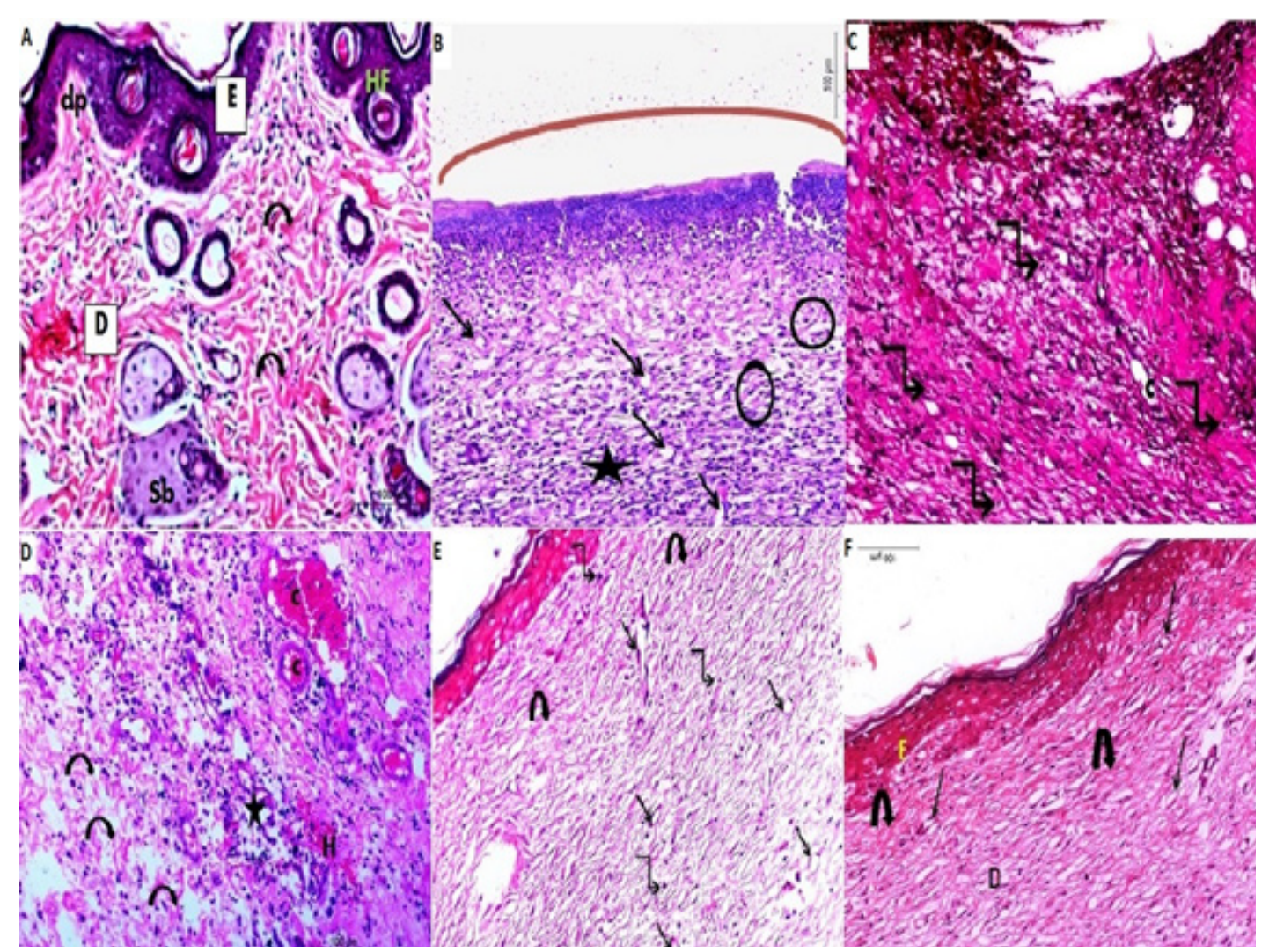

Plate 1: A (GI,control group): a photomicrograph of skin showing thick epidermis(E) with epidermal rete-ridges. The dermis (D) exhibts tightly packed,well organized collagen bundles(curved arrows) with apparent dermal papillae(dp). Multiple hair follicles(HF)and sebecous glands are seen(Sb). B (GIIa, wounded, non diabetic rats): show thin discontinuous epidermis in the site of the wound (the arc).Newly formed blood vessels(thin arrows) and few collagen fibrils overlapped by fibroblasts (the circles). In addition, massive mononuclear cellular infiltrate (the star) can be seen in the dermis. C (GIII, non-treated wounded diabetic rats): The wound bed shows highly cellular granulation tissue with mononuclear cellular infiltrate (articulated arrows) and many congested blood vessels (c).The wound surface shows absent epidermis. 


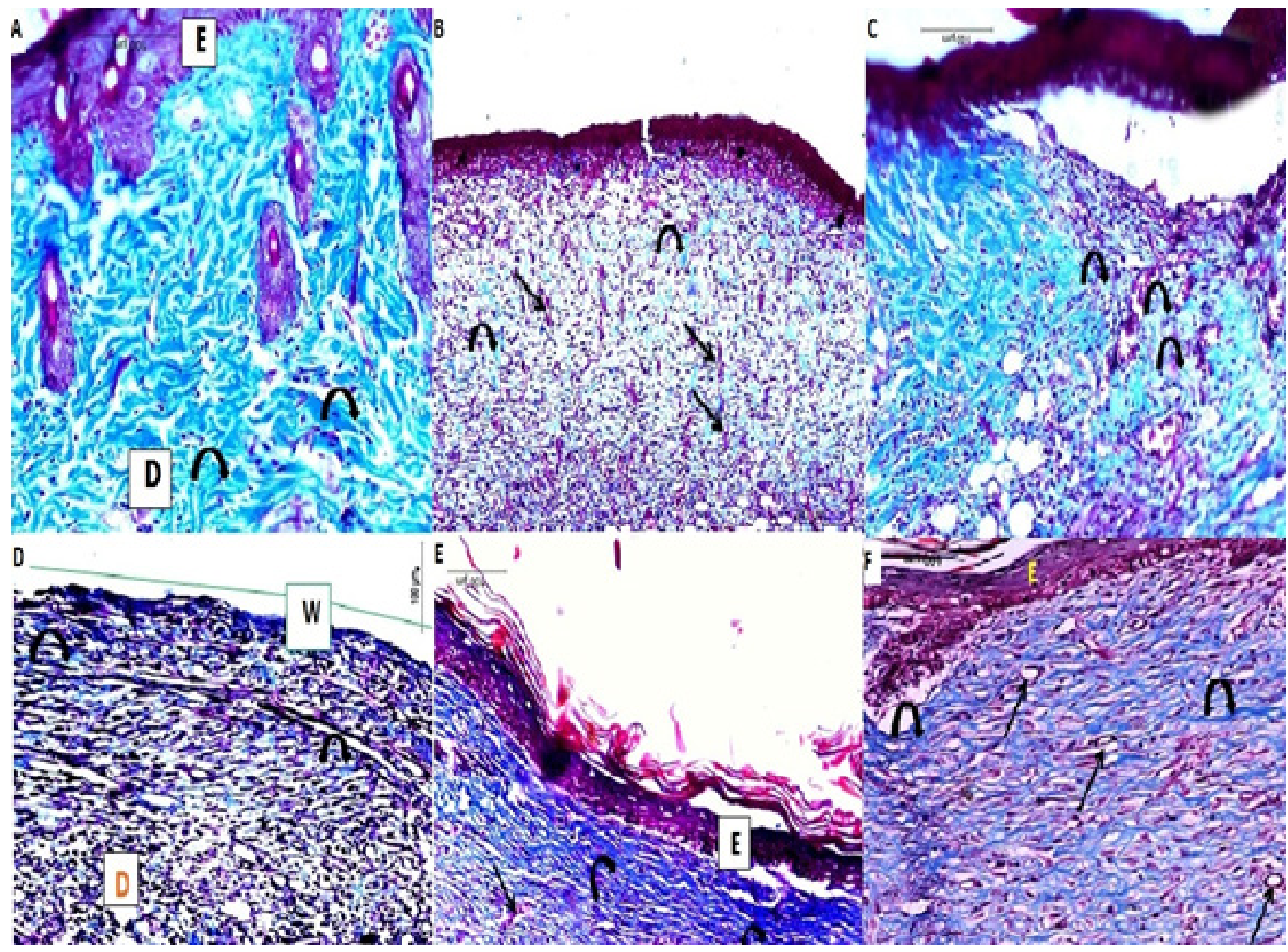

Plate 2:A photomicrograph of skin sectionfrom group (I).The dermis (D) exhibits tightly packed,well organized collagen bundles(curved arrows) and is covered by thick epidermal layer (E). Notice that collagen bundles in papillary layer were thinner than those present in the reticular layer of the dermis which were coarse and dense. B:from subgroup IIa. The dermis shows few thin dispersed collagen fibers (curved arrows) and many new blood vessels (thin arrows). C:skin section in rats of subgroup III a. The wound site shows newly formed collagen fibers (curved arrows). D:skin section from subgroup IVa showing the wound area (W)with absent epidermis. Dermis (D) shows newly formed few thin irregularly arranged collagen fibrils (curved arrows) and disorganized dermal matrix . E:A Photomicrograph of wound section in group Va .The dermis(D) shows newly formed collagen fibers mostly in the upper dermis (curved arrows). Newly formed blood capillaries (thin arrows) and thin epidermis are seen (E).F:A Photomicrograph of wound section in group Va .The dermis(D) shows newly formed collagen fibers mostly in the upper dermis (curved arrows).Newly formed blood capillaries (thin arrows) and thin epidermis are seen (E) . (Masson's trichrome: A, B, C, D,E\&F x200). 


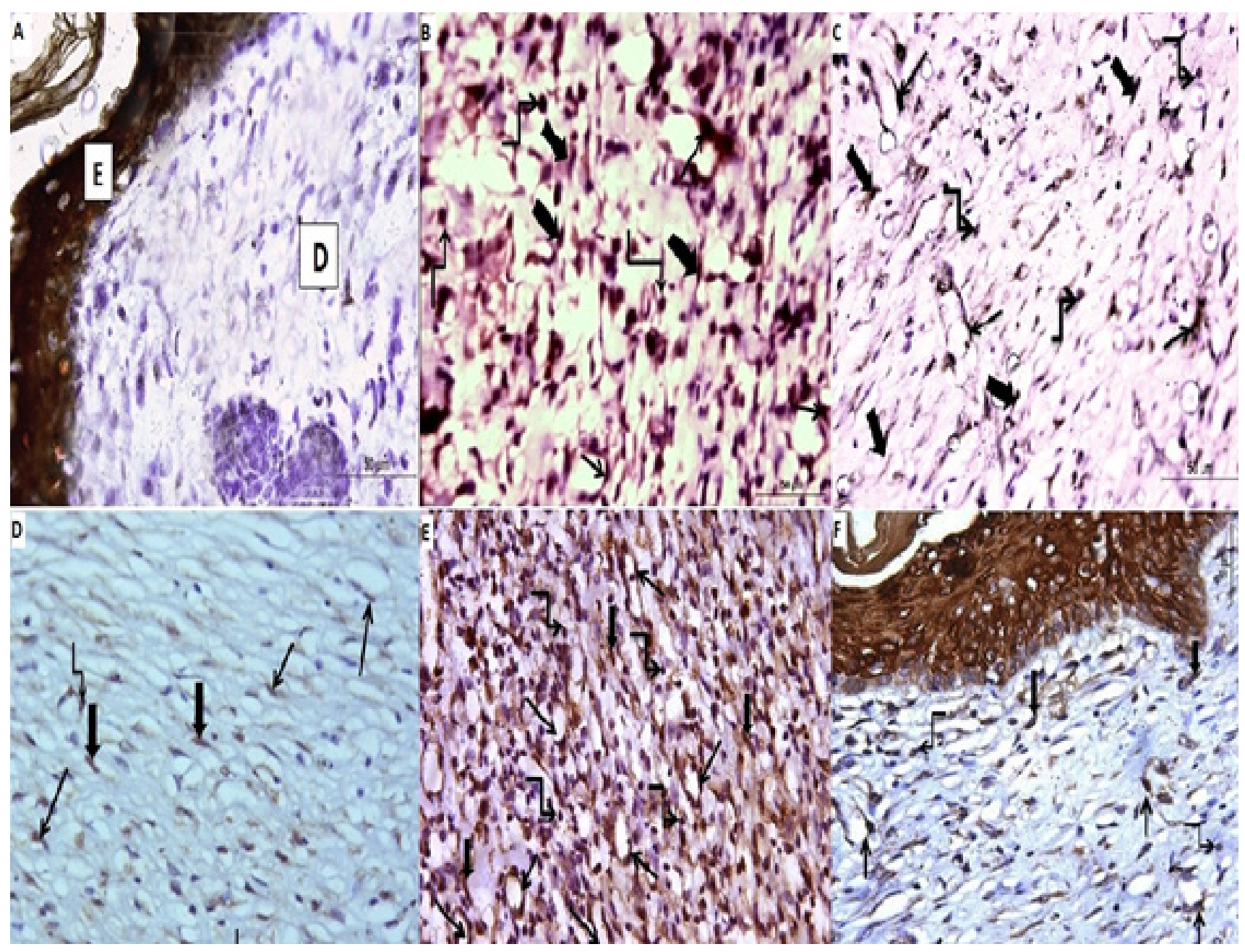

Plate 3: A photomicrograph of skin sections showing A:nearly absent immunoreactivity to VEGF in dermis (D), However, positive cytoplasmic reaction in the epidermal keratinocytes(E).B: Many cells show strong cytoplasmic immunoreacivtity for VEGF : endothelial cells (thin arrows), perivascular mononuclear inflammatory cells (articulated arrows) and fibroblasts (thick arrows). C: moderate positive reaction to VEGFin some endothelial cells (thin arrows), mononuclear inflammatory cells(articulated arrows) and fibroblasts (thickarrows) D: showing the dermis (D) with faint localized positive reaction to VEGF immunohistochemical stain. Reaction is seen in some endothelial cells (thin arrows), fibroblasts (thick arrows) and perivascular mononuclear inflammatory cells (articulated arrow). E:showing strong widespread positive reaction to VEGF immunostaining expressed by large number of endothelial cells (thin arrows), fibroblasts (thick arrows) and perivascular mononuclear inflammatory cells (articulated arrows). F: showing moderate to strong positive reaction for VEGF immunostaining. The reaction is seen in the endothelial cells (thin arrows), fibroblastic cells(thick arrows) and few mononuclear inflammatory cells (articulated arrows).(VEGF immunostaining: A, B, C, D, E \&F x400). 


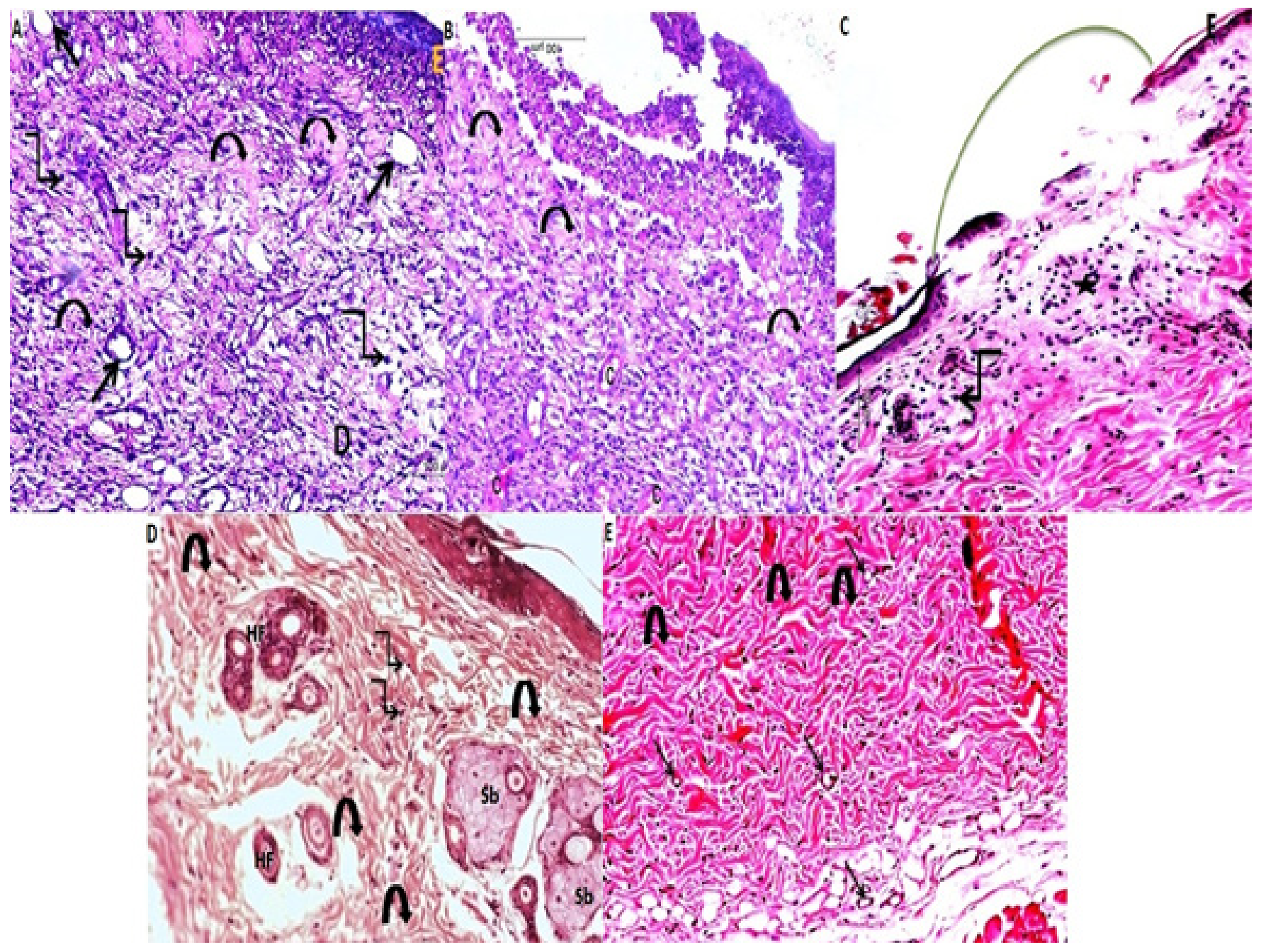

Plate 4: photomicrographs of skin two weaks after wounding of $\mathrm{A}$ (wounded, non diabetic rats) $\mathrm{b}$ showing the wound area covered with the regenerating epidermis (E) . The dermis (D) exhibits massive granulation tissue represented by newly formed disorganized collagen (curved arrows) and many blood vessels (thin arrows). Many inflammatory cells (articulated arrows) are also noticed. B(Non-treated wounded diabetic rats) showing non healed wound with failed epithelial migration. The dermis at the wound area exhibits little disorganized collagen (curved arrows) and some congested blood vessels (c). C (vasline and lanoline treated wounded Diabetic group): The center of the wound area is not covered with epidermis ( green curve). Thin epidermis is covering the edges of the wound (E).The upper dermis is deficient in collagen fibers and shows mononuclear inflammatory cellular infiltrate (star). Perivascular inflammatory cellular (articulated arrow) is also seen. D (ADSCs treated wounded diabetic group) : showing newly formed hair follicles (HF), newly formed sebaceous glands $(\mathrm{Sb})$ and collagen bundles in different directions are seen in the dermis.(curved arrows). Minimal inflammatory cellular infiltrate is seen (articulated arrows). E (atorvastatin treated wounded diabetic group): showing area of wound with thin newly formed epidermis (E) and newly formed epidermal reteridges. The dermis (D) shows newly formed collagen (curved arrows) and newly formed blood vessels (thin arrows). (H\&E: A, B, C, D \& E x200). 


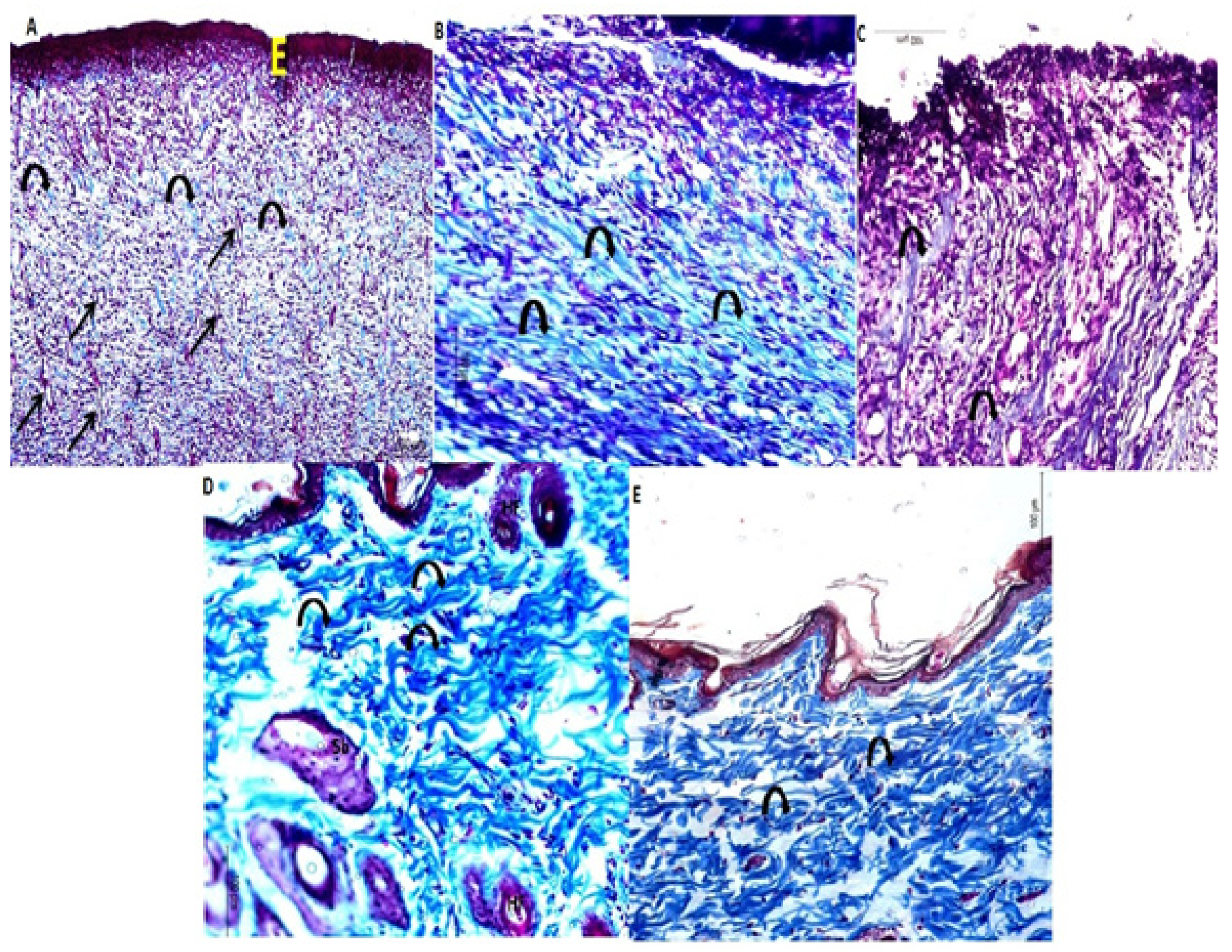

Plate 5: A Photomicrograph of skin sections A: from subgroup II b showing irregularly arranged thin blue-stained collagen fibers ( curved arrows )and many blood vessels( thin arrows) in the dermis. The wound area is completely covered by regenerated epidermis (E).B Photomicrograph of skin section from subgroup III $b$ showing the wound area with disorganized collagen fibers (curved arrows).C subgroup IV b The dermis (D) shows newly formed disorganized collagen fibers (curved arrows). E from subgroup Vb showing collagen bundles in different directions (curved arrows). Skin appendages; hair follicles (HF) and sebaceous glands ( $\mathrm{Sb}$ ) are seen. F in group VI b showing thick disorganizedcollagen bundles are seen (curved arrows). (Masson's trichrome: A, B, C, D\&E x200). 


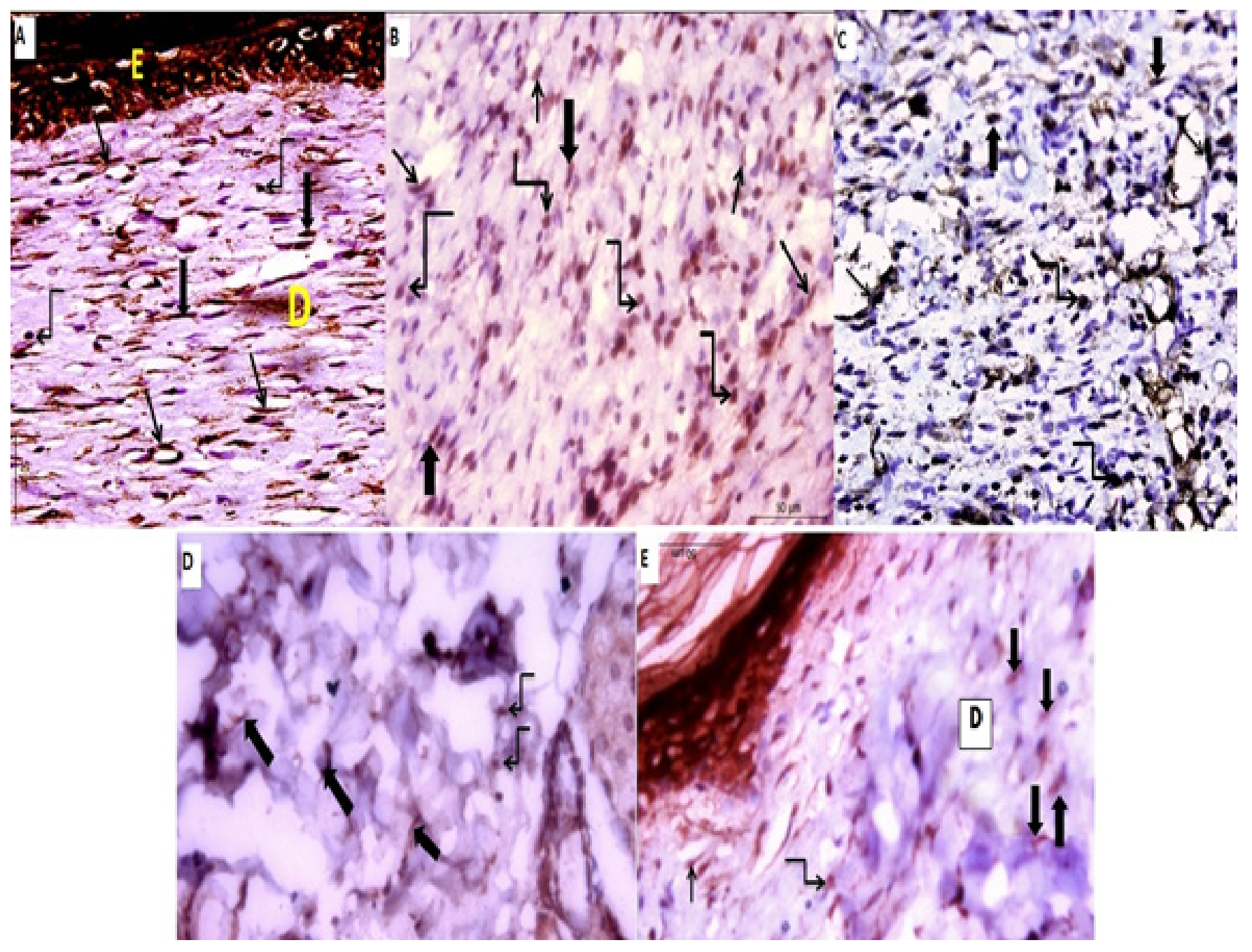

Plate 6: APhotomicrograph of skin section.A:subgroup II b. The dermis (D) exhibits many cells with strong immunoreactivity to VEGF represented by positively reacted endothelial cells (thin arrows), mononuclear inflammatory cells(articulated arrow) and fibroblastic cells (thick arrow).The wound area completely covered with regenerated epidermis. Positive reaction is also seen in epidermal keratinocytes (E). B:subgroup III b showing moderate cytoplasmic reaction to VEGF expressed by positively reacted endothelial cells (thin arrows), mononuclear inflammatory cells(articulated arrows) and fibroblasts (thick arrows). C:from subgroup IVb showing moderate cytoplasmic reaction to VEGF immunostaining in some fibroblastic cells (thick arrows), endothelial cells(thin arrows) and mononuclear inflammatory cells.D:subgroup $\mathrm{V}$ b showing moderate positive immunoreactivity to VEGF in sebaceous glands, and fibroblasts (thick arrows) and few mononuclear inflammatory cells (articulated arrows). E:group VIb showing moderate positive reaction to VEGF in fibroblastic cells (thick arrows), endothelial cells (thin arrows) and mononuclear inflammatory cells (articulated arrows). (VEGF immunostaining: A, B, C, D\& E x400). 

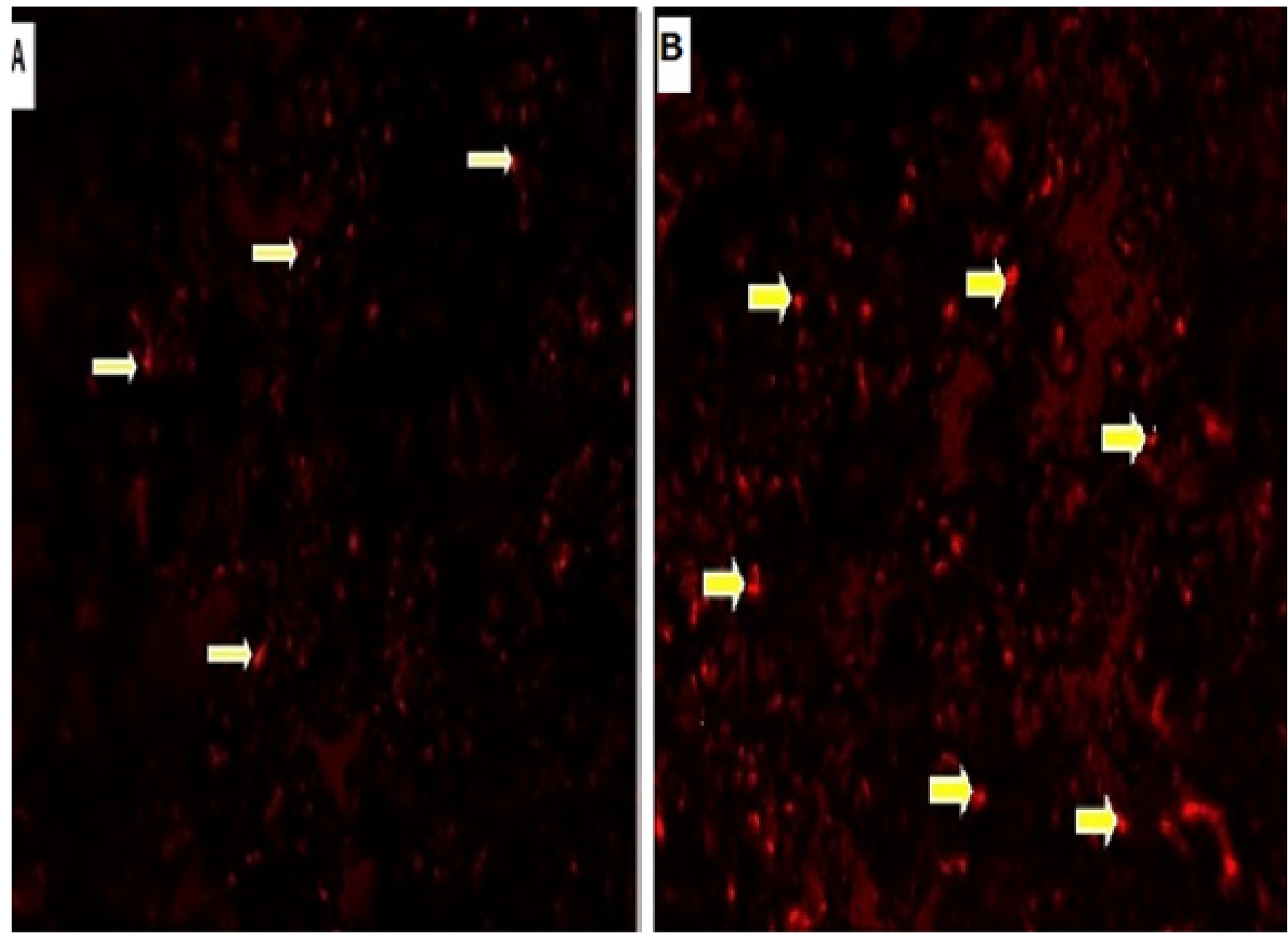

Plate (7) A: Photomicrograph of skin section from subgroup $V$ a showing red fluorescent PKH-labeled adipose stem cells (yellow arrows). B:A photomicrograph of skin section in group IV b showing large number of PKH labeled adipose stem cells (yellow arrows) (A,B :PKH X 400) .

Table 1: The mean epidermal thickness, the mean area percent of collagen fiber and mean area percent for VEGF \pm standerd deviation of the one week subgroups(a)

\begin{tabular}{cccc}
\hline Subgroups (a) & Mean epidermal thickness $(\mu \mathrm{m}) \pm \mathrm{SD}$ & Mean area percent of collagen fibers \pm SD & Mean area percent of VEGF \pm SD \\
\hline I & $54.75 \pm 3.11$ & $39.85 \pm 5.06$ & $12.41 \pm 1.04$ \\
II & $4.76 \pm 2.32^{*}$ & $22.59 \pm 6.23^{*}$ & $22.94 \pm 5.69^{*}$ \\
III & $0 \pm 0$ & $17.71 \pm 0.91$ & $0.74 \pm 0.62$ \\
IV & $0 \pm 00$ & $15.21 \pm 3.69$ & $11.75 \pm 4.86$ \\
V & $19.63 \pm 1.31^{*}$ & $32.18 \pm 2.06^{* *}$ & $44.20 \pm 10.46^{* *}$ \\
VI & $14.08 \pm 2.37^{* *}$ & $29.78 \pm 1.35^{*}$ & $42.39 \pm 2.37^{* *}$ \\
\hline
\end{tabular}

* Significant increase compared to III, IV

** Significant increase compared to II, III ,IV

Table 2: The mean epidermal thickness, the mean area percent of collagen fiber and mean area percent for VEGF \pm standerd deviation of the two weeks subgroups(b)

\begin{tabular}{cccc}
\hline Subgroups (a) & Mean epidermal thickness $(\mu \mathrm{m}) \pm$ SD & Mean area percent of collagen fibers \pm SD & Mean area percent of VEGF \pm SD \\
\hline I & $54.75 \pm 3.11$ & $39.85 \pm 5.66$ & $12.41 \pm 1.04$ \\
II & $16.73 \pm 4.72$ & $26.57 \pm 2.82$ & $33.52 \pm 1.73$ \\
III & $1.76 \pm 1.35$ & $19.06 \pm 1.38$ & $16.75 \pm 4.16$ \\
IV & $1.19 \pm 1.53$ & $18.74 \pm 3.78$ & $24.39 \pm 2.24^{* *}$ \\
V & $40.74 \pm 6.39^{*}$ & $39.08 \pm 5.02^{* *}$ & $22.41 \pm 1.04^{*}$ \\
VI & $26.66 \pm 5.06^{* *}$ & $33.66 \pm 1.66^{*}$ & $* *$ Significant increase compared to II, III ,IV \\
* Significant increase compared to III, IV & &
\end{tabular}




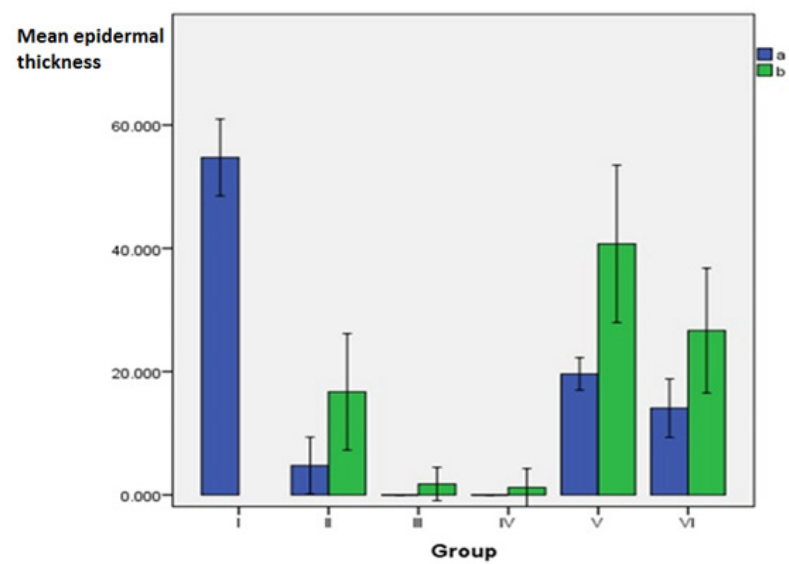

Fig. 1: A histogram of the mean epidermal thickness in $\mathrm{mm}$ for different experimental groups.

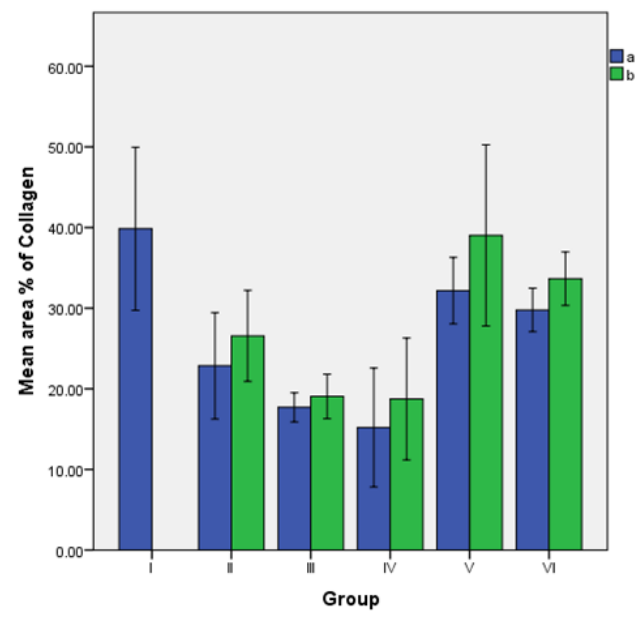

Fig. 2: A histogram of the mean area percent of collagen for different experimental groups.

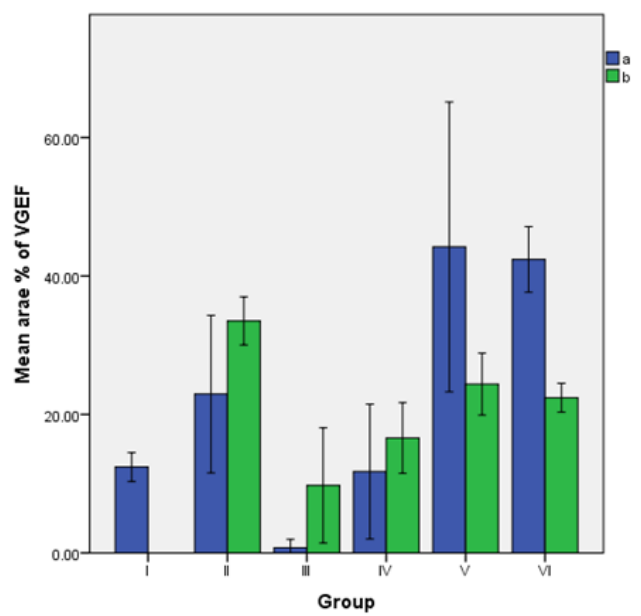

Fig. 3: A histogram of the mean area percent of VEGF for different experimental groups.

\section{DISCUSSION}

$\mathrm{DM}$ is one of the most common chronic diseases all over the world. The diabetic patients are continuously increasing in numbers with increase in representation of diabetic complications ${ }^{[19]}$. The pathogenesis of a diabetic wound is complicated, and involves many factors. Conventional empirical wound care strategies have shown limited efficacy. So, there is an urgent need to develop novel therapeutic strategies ${ }^{[20,21,22]}$.

In the present study, the wound area of the diabetic non treated group III and vasline- lanoline treated group IV after one week (III a, IV a) exhibited delayed epidermal migration which is supposed to be as a result of diabetes. However, the wound edge was covered by proliferated epidermis and excessive inflammatory cellular infiltrate was seen. After 2 weeks, animal of subgroups (III b , IVb) exhibited delayed epidermal regeneration compared to the non -diabetic subgroup II b. Diabetic changes in skin such as perivascular inflammatory infiltrate and congestion of the blood vessels in the dermis were found. Few fine collagen fibers were noted by Masson's trichrome.

The impaired wound healing occurs in DM is due to lack of epithelial migration (absence of the epithelial tongue) at the non-healing wound edge resulted in chronic ulcers. This occurs as the high glucose environment is accompanied by changes in cellular morphology, reduction of proliferation, and abnormal keratinocyte differentiation ${ }^{[19,20]}$.

Hyperglycemia is the main cause of abnormalities and altered healing associated with diabetic wounds. This led to prolonged inflammatory phase, impaired neovascularization, decreased synthesis of collagen, and increased levels of proteases and abnormal macrophage function ${ }^{[23]}$. Blood vessels congestion seen in the subgroup IIIa and Iva explained by tissue hypoxia which leads to degenerative changes and focal areas of necrosis ${ }^{[23,24]}$.

However, some inflammation is beneficial, and necessary for the timely repair of injured skin, while excessive inflammation compromises wound healing outcomes $^{[25]}$. Diabetes leads to chronic persistent inflammatory state of wounds by elevation levels of pro-inflammatory cytokines, reactive oxygen species (ROS) and proteases together with impaired expression of growth factors ${ }^{[24]}$. Some studies concluded that diabetes activates neutrophils to overproduce neutrophils extracellular traps (NETs) which are key factors for wound healing delay ${ }^{[19,26]}$.

Moreover, groups III and IV exhibited a significant decrease in collagen production compared to group II as seen by Masson's trichrome stain. DM leads to decrease in production of collagen fibers by alteration collagenesis causing delay in the healing process through altering the balance between the syntheses, degradation and remodeling of collagen ${ }^{[27]}$. Also, glycation of extracellular 
matrix leads to defective proliferation and migration of dermal fibroblasts ${ }^{[28]}$.

Weak immunoreactivity for VEGF stain was recorded in both subgroups IIIa, IV a compared to non-diabetic subgroup IIa. It exhibited a non-significant increase in subgroups III $b$ and $\mathrm{IVb}$ but still weak reaction. VEGF locally produced by keratinocyte in the wound area is important to stimulate both migration and proliferation of keratinocytes ${ }^{[29]}$. Diabetes cause altered sensitivity to VEGF and decreased its production resulting in impaired wound healing ${ }^{[19,30]}$. Chronic hyperglycemia leads to loss of endothelial cells integrity and increased their susceptibility to apoptosis, detachment and circulation into the blood stream $^{[31]}$.

ADSCs were chosen in this study as a great opportunity for the treatment of chronic wounds, due to the simplicity of the technique and the application of cell treatment in the operating room immediately following debridement ${ }^{[32,33]}$. The capability of ADSCs to secrete growth factors, to differentiate into multiple cell types, and to promote angiogenesis renders them a viable skin substitute ${ }^{[34]}$.

In this study intradermal injection of ADSCs at the edge of the wound was done in group V. The wound of this group appeared more re-epithelialized, normalized and closed than diabetic and vehicle non- treated groups (III and IV). There was rapid subsidence of inflammation and appearance of newly formed blood vessels which represent good degree of angiogenesis with massive granulation tissue. The dermis showed reappearance of skin appendages in the two week subgroup $\mathrm{Vb}$. PKH labeled was detected in the skin subgroup Va with progressive increase in two weeks subgroup $\mathrm{V}$ b. In this study, improvement in the wound of subgroup Va was accompanied with a significant increase in area \% of positive reactivity VEGF compared to subgroups IIIa and IVa. This positive reaction decreased gradually in subgroup $\mathrm{Vb}$ indicating subsidence of new blood vessels formation.

ADSCs promote a new tissue formation rich in vascular structures with remodeling collagen. They also activate fibroblast, keratinocyte proliferation and migration, collagen synthesis and induce angiogenesis. It was suggested that ADSCs are attracted to the wound site and influence regeneration processes via paracrine mechanisms as well as differentiation either for keratinocytes or dermal fibroblasts ${ }^{[32]}$.

It was reported that ADSCs secrete soluble factors that promote angiogenesis, keratinocyte re-epithe $\neg$ lization and protect against apoptosis ${ }^{[34,35]}$. Stem cells accelerate wound healing through activation of other stem cells in tissues, secretion of inflammatory cytokines and growth factors with subsequent increased graft neo-vascularization ${ }^{[36,37]}$.

In agreement with these results, it was reported that VEGF initiate angiogenesis via activation the endothelial cells of existing vessels ${ }^{[38,39]}$. Other researchers suggested that stem cells work through two mechanisms of action, firstly they attenuate the general inflammatory response and secondly, they transform into mature native cell types involved in wound healing such as fibroblasts, antigen presenting cells and endothelial progenitor cells ${ }^{[33,40]}$.

The significant increase in VEGF immunoreactivity in subgroup Va (ADSCs treated) in comparison with subgroups IIIa and IVa could be explained by some authers who reported that ADSCs have angiogenic effects on both endothelial cells and keratinocytes which are sources of VEGF contributing to the acceleration of re-epithelization and wound closure ${ }^{[29,41]}$.

The dermis exhibited appearance of newly formed collagen fibers increased gradually into collagen bundles in different directions in the two week subgroup $\mathrm{Vb}$ and these results was confirmed with Masson's trichrome stain.

Wound healing is a highly regulated process. The mechanisms responsible for full regeneration of the skin or fibrosis (scar formation) are still not obvious ${ }^{[42]}$. The present study revealed reappearance of skin appendages in ADSCs treated wounds. Some researches proved that the use of ADSCs rehearsed the process of skin appendage regeneration and achieved functional recovery of the wounded $\operatorname{skin}^{[43,44]}$.

Typically, wound healing in adult mammals results in scar tissue that lacks skin appendages. Although scar formation can meet the requirements of the skin's fundamental function in preventing infection and dehydration, the scar formed as a result of injuries or burns can result in devastating cosmetic and psychological consequences, reducing the quality of life of the individual ${ }^{[45]}$. Consequently, recovery of skin function is incomplete by scar formation. Thus, the ability to restore the skin to its original state is highly valued ${ }^{[46]}$. This study suggested that intradermal injection of ADSCs at the edge of the wound may be a promising factor to achieve scar-free wound healing. This basic animal study paves the way to clinical trials to control scar formation in diabetic humans. Type I collagen represent the predominant collagen and it produces the greater tensile properties of the normal skin, whereas type III collagen is mainly found in early wound healing stages and is reabsorbed in the later stages. The ideal ratio between type I and type III collagen is important for wound healing and plays vital roles in the prevention of scarring. This ratio is reduced from $4: 1$ to $2: 1$ due to an early increase in the deposition of type III collagen during wound healing. In accordance ASCs increased I /III collagen ratio by increase production of antiscar factor TGF- $\beta 3^{[47]}$.

In group VI the use of topical atorvastatin daily on the wound area exhibited rapid epidermal regeneration, new vessel and collagen formation compared to groups II, III and IV. These results was confirmed by the use of VEGF immunostain which showed high degree of positivity in the one week subgroup (VIa) compared to subgroups II a, III a, IV a indicating its ability for improving angiogenesis. However this positive reaction 
of immunohistochemical stain for VEGF decreased in subgroup VIb suggesting cessation of proliferative phase. Collagen fibers began deposition in subgroup VIa and progressed into disorganized bundles in subgroup VIb. All results of collagen confirmed by Masson's trichrome stain. Atorvastatin, possesses various pleiotropic effects, independently of their cholesterol-lowering function, such as anti-inflammatory, immunomodulatory, antioxidant, metabolic and antibacterial[ ${ }^{[48]}$.

The use of atorvastatin was significantly reduced number of neutrophils, in addition to dampening the pro inflammatory response, reduction of oxidative stress leading to enhanced re-epithelialization and improved vascularization of the wound bed ${ }^{[42]}$. In accordance with other studies, the results of VEGF can be explained by ability of atorvastatin to promote neovascularization via multiple mechanisms which contribute to the beneficial effect of statin therapy on the viability of skin flaps. Atorvastatin treatment improved the blood perfusion, vascular density, and improves endothelial function to secret pro-angiogenic factors including $\mathrm{VEGF}^{[49,50]}$. Treatment with atorvastatin improved the angiogenic responsiveness of endothelial from normal and diabetic rats, but only in the presence of $\operatorname{VEGF}^{[51]}$.

Statins modulate the immune reaction and reduce the inflammation. It promotes an earlier transition from the inflammatory to the proliferative phase which leads to acceleration of the healing proces ${ }^{[51,52]}$.

Comparing the results of both treatments (ADSCs versus atorvastatin) for cautenous wound healing in diabetic rats, according to this study both treatments accelerated wound healing of fully thickened wound in diabetic rats. This was indicated by morphometric study which revealed non-significant difference between the two treated groups in all measured parameters except for epithelial height. However, the ADSCs treated wounds revealed more physiological wound repair than the atorvastatin treated group .As the dermis exhibited more organized collagen bundles with reappearance of skin appendages.

\section{CONCLUSION}

The well-known delayed wound healing with diabetes may be accelerated by topical administration of either ADSCs or atorvastatin by promoting tissue regeneration, re-epithelization, neovascularization as well as formation of collagen and elastic fibers. However, the ADSCs had a better effect as evidenced by reappearance of skin appendages and more organized collagen bundles in the healed wound area.

It is recommended to use ADSCs to accelerate wound healing and prevent scar formation in diabetic patient and as a new strategy for prevention of diabetic foot ulcer. Also, it is advised to try using of ADSCs in other causes of impaired wound healing like some genetic disorders, glucocorticoid treatment and vit $\mathrm{C}$ deficiency.

\section{CONFLICT OF INTERESTS}

There are no conflicts of interest.

\section{REFERANCE}

1. Isakson M., de Blacam C., Whelan D. and McArdle A: Mesenchymal Stem Cells and Cutaneous Wound Healing: Current Evidence and Future Potential. Stem Cells Int; (2015):1822 -1834.

2. Cerqueira M. T., Pirraco R. P. and Marques A. P.: Stem Cells in Skin Wound Healing: Are We There Yet? Adv Wound Care (New Rochelle); (2016) 5(4): 164-175.

3. Wang G, Li w, and Zhao X: Hydrogen sulfide accelerates wound healing in diabetic rats. Int J Clin Exp Pathol; (2015) 8(5):5097-104.

4. Zhou Q., Peng M. and Chen X.: Development and validation of a brief diabetic foot ulceration risk checklist among diabetic patients: a multicenter longitudinal study in China. Sci Rep; (2018) 8(1): 962.

5. Shingyochi $\mathrm{Y} 1$, Orbay $\mathrm{H}$ and Mizuno $\mathrm{H}$ : Adipose-derived stem cells for wound repair and regeneration. Expert Opin Biol Ther; (2015) 15(9):1285-1292.

6. Kullkarni N., Muley M. and Naraynan S.: Topical atorvastatin ameliorates 12-O-tetradecanoylphorbol-13-acetate induced skin inflammation by reducing cutaneous cytokine levels and NF- $\kappa \mathrm{B}$ activation. Arch Pharm Res; (2015) (38):1238-1247.

7. Suzuki-Banhesse VF, Azevedo FF and Lima MH.: Effect of Atorvastatin on Wound Healing in Rats. Biol Res Nurs; (2015)17(2):159-168.

8. Park J., Hwang I., and Kim H.: Atorvastatin prevents endothelial dysfunction in high glucose condition through Skp2-mediated degradation of FOXO1 and ICAM-1. Biochem Biophys Res Commun ; (2018) 495(2):2050-2057.

9. Kuo YR1, Wang CT and Wang CJ.: Adipose-Derived Stem Cells Accelerate Diabetic Wound Healing Through the Induction of Autocrine and Paracrine Effects. Cell Transplant; (2016) 25(1):71-81

10. Ge X, Leow SC, Sathiakumar D and McFarlane $\mathrm{C}$ : Isolation and culture of human adipose-derived stem cells from subcutaneous and visceral white adipose tissue compartments. Bio-protocol; (2016) 6(22): e2027-e2037

11. Mokbel A. El-Tookhy O.and Mostafa A.: Homing and efficacy of intra-articular injection of autologous mesenchymal stem cells in experimental chondral defects in dogs. Clin Exp Rheumatol. ; (2011)29:275-284. 
12. Abdel aziz MT, El Asmar MF and Taha FM.:Efficacy of mesenchymal stem cells in suppression of hepatocarcinorigenesis in rats: possible role of Wnt signaling. J Exp Clin Cancer Res.; (2011) 30:49-57.

13. Alhadlaq, A. and Mao, JJ. : Mesenchymal stem cells; Isolation and therapeutics. Stem Cells Dev;, (2004) 13: 436-448.

14. David Wellington, Igor Mikaelian and Laura Singer:Comparison of Ketamine-Xylazine and Ketamine-Dexmedetomidine Anesthesia and Intraperitoneal Tolerance in RatsJ Am Assoc Lab Anim Sci; (2013 ) 52(4): 481-487.

15. Kiernan JA: Histological and Histochemical Methods: Theory and Practice.5th ed., Scoin publisher, United Kingdom. (2015) pp: 111-162.

16. Bancroft JD and Gamble M: Theory and practice of histological techniques. 6th ed., Churchill Livingstone Elsevier, China. (2008) pp: 433-472.

17. Oh, J.Y., Kim, M.K. and Lee, J.H. (2008): The Anti-Inflammatory and Anti-Angiogenic Role of Mesenchymal Stem Cells in Corneal Wound Healing Following Chemical Injury. STEM CELLS; 26 (4): 1047-1055.

18. Emsley R, Dunn G and White I R: Mediation and moderation of treatment effects in randomized controlled trials of complex interventions. Stat Methods Med Res; (2010) 19(3): 237-270.

19. Avishai E., Yeghiazaryan K., and Golubnitschaja O. : Impaired wound healing: facts and hypotheses for multi-professional considerations in predictive, preventive and personalised medicine. EPMA J.; (2017) 8(1): 23-33.

20. Fekrazad R., Sarrafzadeh A. and Giubellino A.: Improved Wound Remodeling Correlates with Modulated TGF-beta Expression in Skin Diabetic Wounds Following Combined Red and Infrared Photobiomodulation Treatments. Photochem Photobiol; (2018)94(4):775-779.

21. Katsuhiro M, Hui Teoh S, and Yamada T2.: Effects on Glycemic Control in Impaired Wound Healing in Spontaneously Diabetic Torii (SDT) Fatty Rats. Med Arch; (2018) 72(1): 4-8.

22. Tsui HY, Liu YC., and, Tan Q.: Combined effects of artificial dermis and vascular endothelial growth factor concentration gradient on wound healing in diabetic porcine model. Growth Factors; (2018) 35(6):216-224.

23. Al-Hamdany M., Al-Hubaity A. and Al- Omary M: The Histological Changes of the Skin Lesion in Diabetic Foot. Global Journals Inc. (USA). Global J Med Res: C Micro and Path ; (2016)16 (1) : 1-12.
24. El Banna H., El Zorba H. and Kamel W.: Comparative Efficacy of Grotto Cream with Fucidin Cream on Normal and Diabetic Wound Models in Rats. Indian J. physiol Pharmacol; (2018)62(1): 80 -86.

25. Röhl J, Zaharia A, Rudolph M and Murray RZ: The role of inflammation in cutaneous repair. Wound Prac \& Res: J the Australian Wound Management Association; (2015)23 (1): 8-15.

26. Salazar J., Ennis W. and Koh T.: Diabetes Medications: Impact on Inflammation and Wound Healing. J Diabetes Comp; (2016)30(4): 746-752.

27. Wong S., Demers M. and Wagner D.: Diabetes primes neutrophils to undergo NETosis which severely impairs wound healing. Nat Med; (2015)21(7):815-819.

28. Rodrigues H.W.S, Monteiro B.S. and Argôlo Neto N. M.: Stereological and Morphometric Study of Type 3 Collagen Formation in the Cutaneous Wounds of Diabetic Mice Treated with Mesenchymal Stem Cells. Acta Sci Vet; (2018) 46(1): 1553-1564.

29. Asgharia M. , Kanonisabet A. and Bayate M.: The effect of combined photo bio modulation and metformin on open skin. J Photochem Photobiol B; (2017) (169):63-69.

30. Seo E, Lim JS and Jun HS.: Exendin-4 in combination with adipose-derived stem cells promotes angiogenesis and improves diabetic wound healing. J Transl Med; (2017)15(1): 35.

31. Farsaei S., Khalili H. and Farboud E.: Potential role of statins on wound healing: review of the literature. Int Wound J; (2012) 9(3):238-247.

32. Okonkwo U. and Dipietro L.: Diabetes and Wound Angiogenesis. Int J Mol Sci.3; (2017) 18(7): 1419.

33. Zollino I., Zuolo M. and Zamboni P.: Autologous adipose-derived stem cells Basic science, technique, and rationale for application in ulcer and wound healing. Phlebology; (2017) 32(3):160-171.

34. Holm J. S., Toyserkani N. M. and Sorensen J.A. : Adipose-derived stem cells for treatment of chronic ulcers: current status. Stem Cell Res Ther; (2018)9 (1): 142.

35. Kanji S. and Das H.: Advances of Stem Cell Therapeutics in Cutaneous Wound Healing and Regeneration. Mediators Inflamm; 2017 (5217967): 1-14.

36. Rii S., Newman R., and Fink T.: Hypoxia enhances the wound-healing potential of adipose-derived stem cells in a novel human primary keratinocyte-based scratch assay. Int $\mathrm{J}$ Mol Med (2017)39(3): 587-594. 
37. Kavuzlu A., Tatar EÇ., and Korkmaz MH: The effects of the stem cell on ciliary regeneration of injured rabbit sinonasal epithelium. Eur Arch Otorhinolaryngol ; (2017)274(8):3057-3064.

38. Mohan A. and Singh S.: Use of fat transfer to treat a chronic, non- healing, post-radiation ulcer: a case study. J Wound Care ; (2017) 26, (5):272-273.

39. Landén N. , Li D. and Stahle M.:Transition from inflammation to proliferation: a critical step during wound healing. Cell Mol Life Sci; (2016) 73(20): 3861-3885.

40. Wang Q., Xiao D. and Lu M.: The morphological regeneration and functional restoration of bladder defects by a novel scaffold and adipose-derived stem cells in a rat augmentation model. Stem Cell Res Ther; (2017)24; 8(1):149.

41. Koko K. R., Chang S., and Bird D.: Histone Deacetylase Inhibitors Enhance Cytotoxicity Towards Breast Tumors While Preserving the Wound-Healing Function of Adipose-Derived Stem Cells .Ann Plast Surg; (2017)78(6): 728-735.

42. Kolluru G. K., Bir S. C., and Kevil C. G.: Endothelial Dysfunction and Diabetes: Effects on Angiogenesis, Vascular Remodeling, and Wound Healing. Int J Vasc Med; 2012 ( 918267):1-30.

43. Akershoek J., Brouwer K., and Magda M.: Differential effects of Losartan and Atorvastatin in partial and full thickness burn wounds. Burns; (2018)44 (2):429-435.

44. Minjuan W., Jun X. and Kaihong : Hair Follicle Morphogenesis in the Treatment of Mouse Full-Thickness Skin Defects Using Composite Human A cellular Amniotic Membrane and Adipose Derived Mesenchymal Stem Cells. Stem Cells Int; 2016 (82812):35-42.
45. Hashem H., Mobasher M. and Alkhodary A.: Efficiency of Adipose-Derived versus Bone Marrow-Derived Stem Cells in Modulation of Histopathological Changes and CD31 Immunoexpression during Wound Healing in Rats. J Biochem Cell Biol; (2018) 1(1): 2-9.

46. Li L. Rutlin M. and Ginty DD: The functional organization of cutaneous low-threshold mechanosensory neurons. Cell; (2011) 147(7): 1615-1627.

47. Takeo M. Wendy Lee and Ito M.: Wound Healing and Skin Regeneration. Cold Spring Harb Perspect Med; (2015) 5(1):a023267-023279.

48. Wang J., Hao H., and Han W.: The Effect of Adipose-Derived Stem Cells on Full-Thickness Skin Grafts. BioMed Res Int; 2016 (1464725):25-35

49. Ala S, Alvandipour $M$ and Faramarzi F: Effects of Topical Atorvastatin (2\%) on Post-hemorrhoidectomy Pain and Wound Healing: A Randomized Double-Blind Placebo-Controlled Clinical Trial. World J Surg; (2017)41(2):596-602.

50. Chen JX, Chiu CW and Shih PK: The effect of atorvastatin on survival of rat ischemic flap. Kaohsiung J Med Sci; (2013) (187):192-193.

51. Jia YC, Xu J and Chai YM :The Effect of Atorvastatin on the Viability of Ischemic Skin Flaps in Diabetic Rats. Plast Reconstr Surg; (2017)139(2):425e-433e.

52. Chaudagar Kiranj K and Mehta Anita A.: Effect of atorvastatin on the angiogenic responsiveness of coronary endothelial cells in normal and streptozotocin (STZ) induced diabetic rats. Can. J. Physiol. Pharmacol; (2014) 92: 338-349. 
الملخص العربى

دراسة هستولوجيةوكيميائيه مناعيه على تأثير عقار الاتورفاستاتين مقابل الخلايا

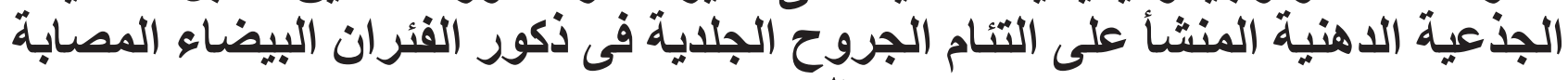
بالسكرى

عبير فؤادعبد المحسن'، نجلاء محمد سلامة'، داليا حسين عبد العزيز، عزه صالح معوض امبابي'،

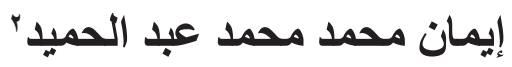

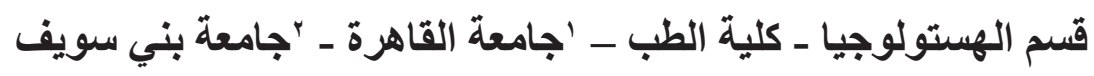

مقدمه: حو الي 0 \% \$من • 10 مليون انسان مريض بالسكري حول العالم يعاني من قرح القدم والتي عاده تصبح مزمنه

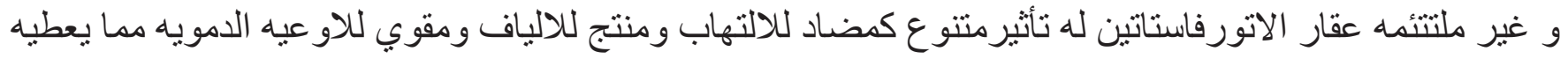

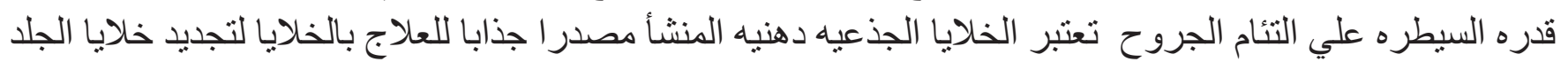

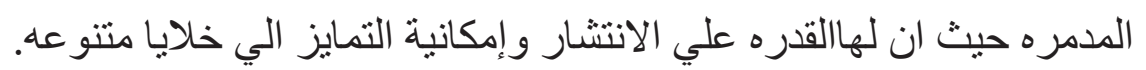

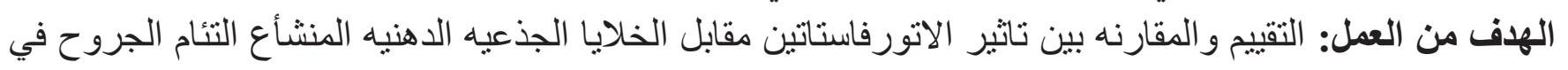
الفئر ان المصابه بالسكري.

المواد والطرق المستخدمه: 72فأر اكلا منها تم تقسيمها الي ست مجمو عات كلا منها قسمت الي مجمو عات فرعيه أ و ب طبقا لميعاد التضحيه كالاتي :مجمو عه فر عيه (أ):تم التضحيه بها بعد اسبوع من بدايه الجرحمجمو عه فرعيه (ب):تم التضحيه بها بعد 14يوممن بدايه الجرح

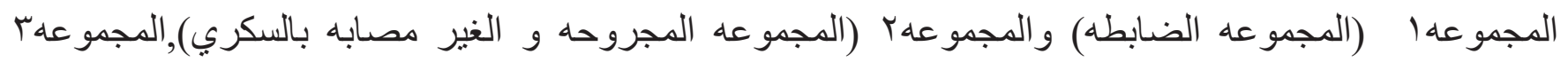

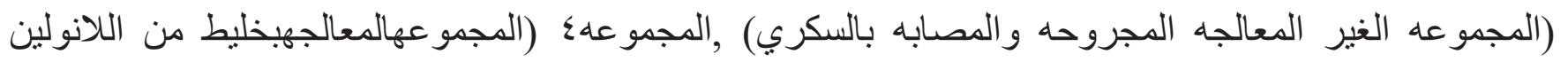

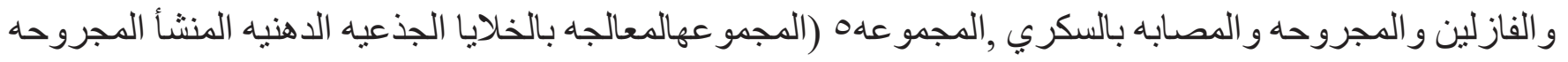

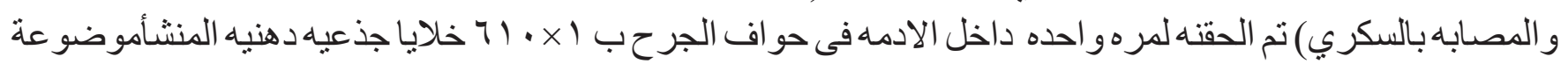

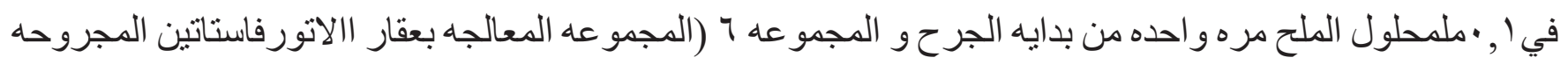

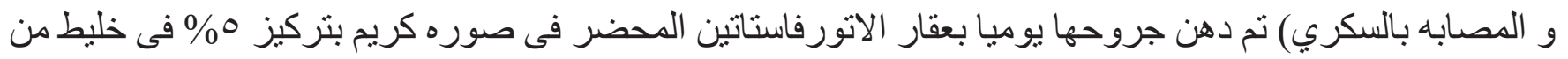

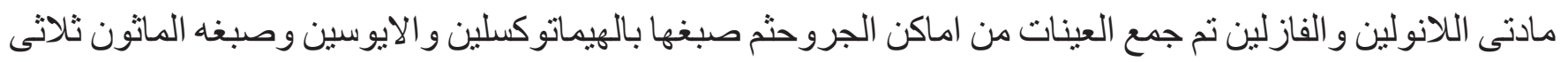

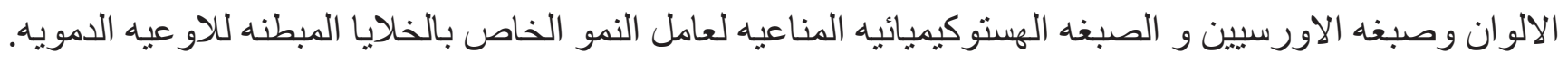

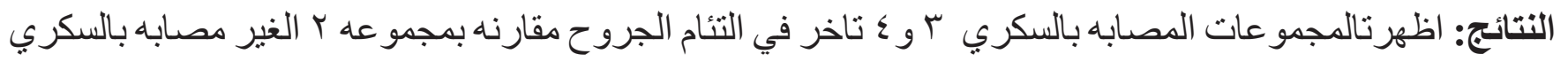
تأخر تكون الغشاء الطلائي حيث اظهرت جروحها تفاعلات منخفضه الي متوسطه للصبغه المناعيه الهستوكيميائيه

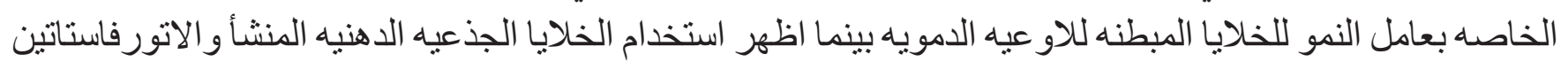

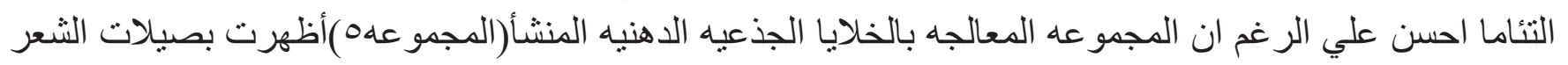
بوضوح و التي تم افتقادها في المجمو عه المعالجه بالاتور فاستاين(المجمو عهاجآ).

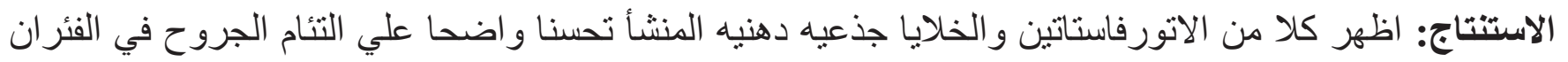

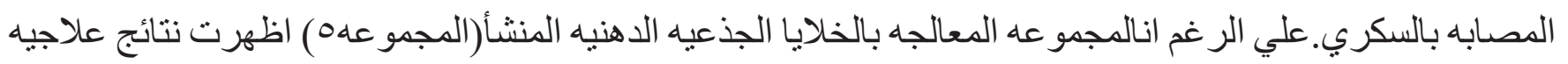

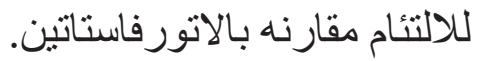

